\title{
SMR
}

\section{Post-transcriptional silencing of the SGE1 gene induced by a dsRNA hairpin in Fusarium oxysporum f. sp cubense, the causal agent of Panama disease}

\author{
J.S. Fernandes ${ }^{1}$, P.C.S. Angelo ${ }^{2}$, J.C. Cruz ${ }^{1}$, J.M.M. Santos ${ }^{3}$, N.R. Sousa ${ }^{4}$ and \\ G.F. Silva ${ }^{1}$ \\ 'Laboratório de Biologia Molecular, Embrapa Amazônia Ocidental, Manaus, AM, \\ Brasil \\ ${ }^{2}$ Embrapa Café - Fundação Procafé, Varginha, MG, Brasil \\ ${ }^{3}$ Instituto Nacional de Pesquisa da Amazônia \& Universidade do Estado do Amazonas, \\ Manaus, AM, Brasil \\ ${ }^{4}$ Embrapa Cocais, São Luiz, MA, Brasil \\ Corresponding author: G.F. Silva \\ E-mail: gilvan.silva@embrapa.br
}

Genet. Mol. Res. 15 (2): gmr.15027941

Received October 28, 2015

Accepted December 9, 2015

Published April 4, 2016

DOI http://dx.doi.org/10.4238/gmr.15027941

ABSTRACT. Fusarium oxysporum f. sp cubense (Foc), the causal agent of Panama disease, is responsible for economic losses in banana crops worldwide. The identification of genes that effectively act on pathogenicity and/or virulence may contribute to the development of different strategies for disease control and the production of resistant plants. The objective of the current study was to analyze the importance of SGE1 gene expression in Foc virulence through post-transcriptional silencing using a double-stranded RNA hairpin. Thirteen transformants were selected based on different morphological characteristics, and sporulation in these transformants was significantly reduced by approximately $95 \%(P<0.05)$ compared to that of the wild-type strain. The relative SGE1 expression 
levels in the transformant strains were reduced by 27 to $47 \%$ compared to those in the wild-type strain. A pathogenicity analysis revealed that the transformants were able to reach the rhizomes and pseudostems of the inoculated banana plants. However, the transformants induced initial disease symptoms in the banana plants approximately 10 days later than that by the wild-type Foc, and initial disease symptoms persisted even at 45 days after inoculation. These results indicate that the SGE1 gene is directly involved in the virulence of Foc. Therefore, SGE1 may be a potential candidate for host-induced gene silencing in banana plants.

Key words: Gene silencing; F. oxysporum f. sp cubense; SGE1; FOC

\section{INTRODUCTION}

The filamentous fungus Fusarium oxysporum f. sp cubense (E.F. Smith) Snyder \& Hansen (Foc) is the causal agent of Panama disease in banana plants. Panama disease has caused extensive damage to banana-production in areas of Asia, Africa, and the Americas for decades (Ploetz and Pegg, 1997; FAO, 2014). According to the Food and Agriculture Organization of the United Nations, this disease has wreaked havoc in many countries in recent years by directly and indirectly affecting the producers, traders, and families who depend on the banana industry. Panama disease cannot be controlled by fungicides, and thus the way its spread is prevented is by controlling the circulation of diseased plant materials (Cordeiro and Matos, 2003; FAO, 2014), and the use of resistant cultivars, which is considered the most economically and environmentally feasible approach (Cordeiro and Matos, 2003). However, increased genetic variability in this plant pathogen can overcome resistance. This can hinder the use of cultivars for extended periods, and thus requires the constant production of new resistant cultivars or the establishment of new disease control strategies.

Post-transcriptional gene silencing using RNA interference, also known as RNAi knockdown, is an advantageous method to control gene expression because it is highly specific to the target mRNA. Additionally, RNAi efficiency is not affected by the presence of dikaryotic nuclei or multicopy genes (Fire et al., 1998; França et al., 2010). As such, RNAi is a cellular defense mechanism used by fungi and various other organisms (Napoli et al., 1990; Romano and Macino, 1992; Fire et al., 1998; Ketting et al., 1999). RNAi can also be used to control diseases caused by plant pathogens by reducing the expression level of various genes that may be involved in virulence.

The fungal RNAi mechanism utilizes double-strand RNA (dsRNA) (Fire et al., 1998; Elbashir et al., 2001). dsRNA can be produced in situ by fungi, or prepared in vitro and transferred into cells, which is known as synthetic RNAi (Caribé dos Santos et al., 2009; Mumbanza et al., 2013). The construction of DNA vectors containing cassettes that encode for long dsRNA hairpins targeting specific genes, and the subsequent insertion of these cassettes into the genomes of organisms of interest allow for the permanent silencing of the target mRNA. This differs from the transfection of synthetic dsRNAs or small interfering RNAs (siRNAs), which produce transient gene silencing (Krajaejun et al., 2007; Shafran et al., 2008; Bhadauria et al., 2009; Caribé dos Santos et al., 2009; Mumbanza et al., 2013).

Recently, Sutherland et al. (2013) detected the presence of pathogenicity-related genes in the tropical race 4 (TR4) and subtropical race 4 (STR4) Foc strains. Several other genes were also identified by Guo et al. (2014) in a comparative analysis between the genomes and transcriptomes 
of Foc races R1 and R4. Particularly, a gene known as SIX Gene Expression 1 (SGE1), identified in F. oxysporum f. sp licopercisi (Fol) by Michielse et al. (2009), has drawn considerable attention. SGE1 encodes for a homonymous protein with transcription factor function that is capable of activating the transcription of effector genes that encode for a family of proteins termed secreted in xylem (SIX). SIX proteins are directly involved in the infectious process of the host plant (Michielse et al., 2009). The presence of Six1 through Six10 has been reported in Fol (Rep et al., 2004; Lievens et al., 2009; Meldrum et al., 2012), and some of these genes have already been detected in Foc (Meldrum et al., 2012). Fol strains containing mutations in the SGE1 gene were unable to cause disease in tomato plants, although conidiogenesis was affected, albeit without altering the viability of the generated spores (Michielse et al., 2009).

Given the importance of the SGE1 gene in pathogenicity, the objective of the current study was to assess whether the SGE1 gene plays a functional role in Foc and to evaluate morphophysiological changes in transformants with differing levels of SGE1 silencing.

\section{MATERIAL AND METHODS}

\section{Microorganisms and culture conditions}

The Foc R2 isolate (VCG 0124) and the Agrobacterium tumefaciens strain AGL1 were used in genetic transformation experiments. Foc R2 was routinely grown on potato dextrose agar (PDA) medium (10 g/L dextrose; $16 \mathrm{~g} / \mathrm{L}$ agar; $250 \mathrm{~g} / \mathrm{L}$ potato discs) and maintained in an incubator at $25^{\circ} \mathrm{C}$. PDA cubes $\sim 0.5 \mathrm{~mm}^{2}$ in size containing mycelia were removed from Petri dishes and placed in flasks with $50 \mathrm{~mL}$ potato dextrose broth (PDB) at $1 / 4$ normal concentration. Flasks were stirred at $150 \mathrm{rpm}$ for $48 \mathrm{~h}$ to prepare conidia. The A. tumefaciens strain AGL1 was transformed with a binary vector carrying an RNAi construct for SGE1 gene silencing. Bacteria were grown in solid and liquid LB-mannitol culture medium (10 g/L tryptone; $5 \mathrm{~g} / \mathrm{L}$ yeast extract; $2.5 \mathrm{~g} / \mathrm{L} \mathrm{NaCl}$; $16 \mathrm{~g} / \mathrm{L}$ agar; $10 \mathrm{~g} / \mathrm{L}$ mannitol) supplemented with antibiotics $(75 \mu \mathrm{g} / \mathrm{mL}$ carbenicillin and $50 \mu \mathrm{g} / \mathrm{mL}$ kanamycin), and incubated at $28^{\circ} \mathrm{C}$ for $24-48 \mathrm{~h}$.

\section{Construction of a binary vector for SGE1 gene silencing in Foc by RNAi knockdown}

RNAi gene silencing was achieved using a specific dsRNA hairpin to silence transcripts produced by the targeted gene (SGE1) in Foc. The vector pFANTAi4 (Krajaejun et al., 2007) was kindly provided by Dr. Thomas D. Sullivan at the University of Wisconsin. A SGE1 gene fragment 564 base pairs (bp) in length was cloned into pFANTAi4 in sense and antisense orientations. Sense and antisense sequences of the green fluorescent protein (GFP) reporter gene, a spacer region, and a terminator region were also present in the cassette, and the expression of all cassette components was under the control of the Histoplasma capsulatum histone $2 \mathrm{AB}$ constitutive promoter. The construct also included a gene conferring resistance to hygromycin ( $h p h)$.

\section{Genetic transformation of Foc measured using $A$. tumefaciens-mediated transformation (ATMT)}

Transformation was performed using the ATMT procedure according to methods described by Zwiers and De Waard (2001), with some modifications. Conidia and protoplasts were used for 
transformation. Conidia were prepared using the culture conditions described above. The spore culture was filtered through sterile gauze, centrifuged, and washed twice with ultrapure autoclaved $\mathrm{H}_{2} \mathrm{O}$. Conidia were diluted in induction medium [10 mL/L K-buffer, $\mathrm{pH} 6.8 ; 1 \mathrm{~mL} / \mathrm{L} 1 \% \mathrm{CaCl}_{2} ; 10$ $\mathrm{mL} / \mathrm{L} 0.1 \% \mathrm{FeSO}_{4} ; 2.5 \mathrm{~mL} / \mathrm{L} 20 \% \mathrm{NH}_{4} \mathrm{NO}_{3} ; 20 \mathrm{~mL} / \mathrm{L} \mathrm{M}-\mathrm{N} ; 5 \mathrm{~mL} / \mathrm{L}$ spore elements; $10 \mathrm{~mL} / \mathrm{L} 50 \%$ glycerol; $40 \mathrm{~mL} / \mathrm{L} 1 \mathrm{M}$ MES, pH 4.8; $8.75 \mathrm{~mL} / \mathrm{L} 20 \%$ glucose; and $1 \mathrm{~mL} / \mathrm{L} 200 \mu \mathrm{M}$ acetosyringone (AS)], and the concentration was adjusted to $10^{6} \mathrm{spores} / \mathrm{mL}$. Protoplasts were prepared according to methods described by Visser et al. (2004), with some modifications, i.e., only the lysing enzyme solution was used (Sigma-Aldrich; $100 \mathrm{mg} / \mathrm{mL}$ diluted in osmotic medium), whereas the enzyme mixture was not used.

The AGL1 strain containing the vector pFANTAi4 was grown in LB-mannitol liquid medium supplemented with antibiotics ( $75 \mu \mathrm{g} / \mathrm{mL}$ carbenicillin and $200 \mu \mathrm{g} / \mathrm{mL}$ spectinomycin). Bacteria were incubated in a shaker $(200 \mathrm{rpm})$ at $28^{\circ} \mathrm{C}$ for $24 \mathrm{~h}$. The bacterial culture was then centrifuged, and the supernatant was discarded. Minimum medium $(10 \mathrm{~mL} / \mathrm{L} \mathrm{K}$-buffer, $\mathrm{pH}$ 6.8; $1 \mathrm{~mL} / \mathrm{L} 1 \%$ $\mathrm{CaCl}_{2} ; 10 \mathrm{~mL} / \mathrm{L} 0.1 \% \mathrm{FeSO}_{4} ; 2.5 \mathrm{~mL} / \mathrm{L} 20 \% \mathrm{NH}_{4} \mathrm{NO}_{3} ; 20 \mathrm{~mL} / \mathrm{L} \mathrm{M}-\mathrm{N} ; 5 \mathrm{~mL} / \mathrm{L}$ spore elements; 8.75 $\mathrm{mL} / \mathrm{L} 20 \%$ glucose) was added, and the culture was incubated at $200 \mathrm{rpm}$ and $28^{\circ} \mathrm{C}$ overnight. Subsequently, the bacterial culture was centrifuged and resuspended in induction medium (IM). The optical density at $600 \mathrm{~nm}\left(\mathrm{OD}_{600 \mathrm{~nm}}\right)$ was measured for 0.15 and 0.5 dilutions. A culture period of $\sim 3$ to $4 \mathrm{~h}$ was allowed so that the OD of the 0.15 dilution reached 0.18 and the OD of the 0.5 dilution reached 0.6-0.8.

Protoplast and microconidium cultures were co-cultured with Agrobacterium at a 1:1 ratio ( $3 \mathrm{~mL}$ Foc protoplasts or spores and $3 \mathrm{~mL}$ Agrobacterium culture). Cultures were incubated at $22^{\circ} \mathrm{C}$ for 48 or $96 \mathrm{~h}$. A total of $100 \mu \mathrm{L}$ co-culture was spread onto Petri dishes containing PDA medium supplemented with antibiotics (130 $\mu \mathrm{g} / \mathrm{mL}$ hygromycin B and $400 \mu \mathrm{g} / \mathrm{mL}$ cefotaxime) to select for transformants. Plates were maintained in an incubator at $25^{\circ} \mathrm{C}$ until transformant mycelia were visualized. The remainder of the co-culture was centrifuged. The IM was discarded, and $6 \mathrm{~mL}$ PDB supplemented with $130 \mu \mathrm{g} / \mathrm{mL}$ hygromycin B and $400 \mu \mathrm{g} / \mathrm{mL}$ cefotaxime was added. Cultures were divided into three aliquots of $2 \mathrm{~mL}$ each. Culture aliquots were kept on a shaker (150 rpm) at $25^{\circ} \mathrm{C}$ until mycelial growth was visualized. The monospore culture procedure was followed for transformants prepared in PDB medium.

\section{DNA extraction}

Wild-type isolates and transformants were grown in PDB medium under $150 \mathrm{rpm}$ stirring for three days to prepare a mycelial mass. Total DNA extraction was performed according to the cetyltrimethylammonium bromide method as previously described (Doyle and Doyle, 1990). The DNA extract was treated with RNAse (Invitrogen, Carlsbad, CA, USA), quantified by spectrophotometry (NanoDrop, Thermo Fisher, Waltham, MA, USA), and subjected to $0.8 \%$ agarose gel electrophoresis.

\section{Confirmation of transformants}

The presence of the hygromycin resistance marker gene $(h p h)$ in the possible transformants was detected by polymerase chain reaction (PCR) and used to confirm the integration of the T-DNA cassette into the genome. The amplification reaction was performed on $2 \mu \mathrm{L}$ total DNA (50 ng) from transformants or untransformed fungus (wild-type). PCR was performed in a $15-\mu \mathrm{L}$ reaction volume, which contained $0.3 \mu \mathrm{M} h p h$ forward and reverse primers (Table 1), 1.5 $\mu \mathrm{L} 1 \mathrm{X}$ reaction 
buffer (500 mM KCl; $100 \mathrm{mM}$ Tris- $\mathrm{HCl}, \mathrm{pH}$ 8.4; $1 \%$ Triton X-100), $1.2 \mu \mathrm{L} \mathrm{MgCl}_{2}(1.5 \mathrm{mM}), 1.6 \mu \mathrm{L}$ dNTPs $(0.8 \mathrm{mM}), 1 \cup$ Taq polymerase (Phoneutria), and brought to a total volume of $15 \mu \mathrm{L}$ with distilled water. The following PCR conditions were used: $94^{\circ} \mathrm{C}$ for $3 \mathrm{~min}$ as an initial denaturation step; followed by 30 cycles of $94^{\circ} \mathrm{C}$ for $30 \mathrm{~s}$ for denaturation, $66^{\circ} \mathrm{C}$ for $30 \mathrm{~s}$ for primer annealing, and $72^{\circ} \mathrm{C}$ for $1 \mathrm{~min}$ for DNA strand synthesis; and a final extension at $72^{\circ} \mathrm{C}$ for $10 \mathrm{~min}$. Amplified products were visualized following $1.5 \%$ agarose gel electrophoresis.

Table 1. Oligonucleotide sequences used in the current study.

\begin{tabular}{|c|c|c|c|c|c|}
\hline Primers & Gene identification & Forward primer 5'- 3' & Reverse primer $5^{\prime}-3^{\prime}$ & $\begin{array}{l}\text { Product } \\
\text { size }\end{array}$ & $\mathrm{T}\left({ }^{\circ} \mathrm{C}\right)$ \\
\hline SGE1 & SGE1 gene & ATCTGGTCGGTTCACTCGTC & ACCACGCCTGACCATAAGAC & $600 \mathrm{bp}$ & $60^{\circ} \mathrm{C}$ \\
\hline$h p h$ & Hygromycin B & TTCGATGTAGGAGGGCGTGGAT & CGCGTCTGCTGCTCCATACAAG & $690 \mathrm{bp}$ & $66^{\circ} \mathrm{C}$ \\
\hline SGE1ds & dsRNA - SGE1 & TCTGTCCCTTTCCAAACAGG & CGTACGAGTCGACGAGTGAA & $100 \mathrm{bp}$ & $60^{\circ} \mathrm{C}$ \\
\hline SGE1silence & SGE1 gene & TTGCCTAGTCCTGTGGATGA & TGTGTGTGGGAAAGCCAATA & $175 \mathrm{bp}$ & $60^{\circ} \mathrm{C}$ \\
\hline tef & Elongation factor & ACAAGCGAACCATCGAGAAG & GATGAAATCACGGTGACCG & $243 \mathrm{bp}$ & $60^{\circ} \mathrm{C}$ \\
\hline$g 6 p d$ & $\begin{array}{l}\text { Glucose-6- } \\
\text { phosphate 1- } \\
\text { dehydrogenase }\end{array}$ & ACATTCCCCGAAACGAGCTT & ATGCTGAGACCAGGCAGCTT & $88 \mathrm{bp}$ & $60^{\circ} \mathrm{C}$ \\
\hline gapdh & $\begin{array}{l}\text { Glyceraldehyde 3- } \\
\text { phosphate }\end{array}$ & CCAGATCAAGAAGGTCATCAAG & GTTGGTGTTGCCGTTGAGAT & $106 \mathrm{bp}$ & $60^{\circ} \mathrm{C}$ \\
\hline
\end{tabular}

\section{Transformant mitotic stability test}

Transformants isolated by monospore culture were maintained in selective medium (PDA supplemented with $130 \mu \mathrm{g} / \mathrm{mL}$ hygromycin) for 20 days. Subsequently, 13 transformants prepared from four different experiments were selected for mitotic stability and expression tests. The end fragments of transformant colonies were transferred to Petri dishes containing antibiotic-free PDA, and five successive subcultures were performed at four-day intervals. Following this procedure, mycelial fragments derived from the final subculture were again transferred to plates containing PDA supplemented with $130 \mu \mathrm{g} / \mathrm{mL}$ hygromycin $\mathrm{B}$, and incubated in a biological oxygen demand (BOD) incubator at $25^{\circ} \mathrm{C}$.

\section{Vegetative growth and sporulation analysis}

The radial size of colonies of the 13 selected transformants and the radial size of the untransformed fungus (wild-type Foc) were compared, and the effect of SGE1 silencing on the growth of transformants was analyzed. The vegetative growth of transformants was compared to wild-type growth after 7 days of culture.

To evaluate sporulation, mycelial and spore solutions were analyzed between 3 and 7 days of growth in $1 / 4$ strength PDB. The evaluations were performed using five treatments (T2, T4, $\mathrm{T7}, \mathrm{T11}$, and wild-type) with five replicates each. The results were subjected to analysis of variance using the SISVAR software (Universidade Federal de Lavras, Lavras, MG, Brazil). The means were compared using the Tukey test at $5 \%$ probability.

\section{RNA extraction, cDNA synthesis, and reverse transcription-quantitative PCR (RT- qPCR)}

Gene expression in the 13 selected transformed strains was measured from mycelium collected before and after the mitotic stability test. Total RNA from the mycelial mass of transformants 
and wild-type isolates was extracted using the RNeasy Mini Kit (QIAGEN, Hilden, Germany) according to manufacturer specifications. Quantification of extracted RNA was performed using a NanoDrop spectrophotometer (Thermo), and the quality was confirmed by $1.2 \%$ agarose gel electrophoresis. Furthermore, $4 \mu \mathrm{g}$ total RNA was treated with DNase (Invitrogen), and following digestion, the RNA was assessed by $1.2 \%$ agarose gel electrophoresis.

cDNA was synthesized using the High-Capacity cDNA Reverse Transcription Kit (Applied Biosystems, Foster City, CA, USA) following manufacturer instructions. The absence of genomic DNA was confirmed by PCR amplification of the tef gene, which has a 469-bp genomic DNA amplicon and a cDNA amplicon of approximately $200 \mathrm{bp}$.

The cDNA used in the reactions was diluted to a $1: 10$ ratio $(\mathrm{v} / \mathrm{v})$, and $2 \mu \mathrm{L}$ dilution was used for RT-qPCR, with $0.25 \mathrm{nM}$ primers (Table 1). All reactions were performed in triplicate.

RT-qPCR analysis was performed using the Fast SYBR Green Master Mix and a 7500 Real time PCR System (Applied Biosystems). Three primer pairs for internal reference genes (tef, g6pd, and gapdh) were used in addition to the primer pairs SGE1ds and SGE1 silence directed to the SGE1 transcript. The SGE1ds forward and reverse primers were designed to amplify a 100-bp fragment of SGE1 also included in the 564-bp dsRNA construct. The SGE1 silence forward and reverse primers were used to quantify SGE1 gene silencing. These last primers were capable of amplifying a 175-bp fragment outside the region covered by the synthetic dsRNA (Figure 1). The relative expression for the dsRNA and the SGE1 gene before and after the mitotic stability test was analyzed in the 13 Foc selected isolates. The relative expression was calculated using the $2^{-\Delta \Delta C T}$ method, using the software provided by Applied Biosystems.

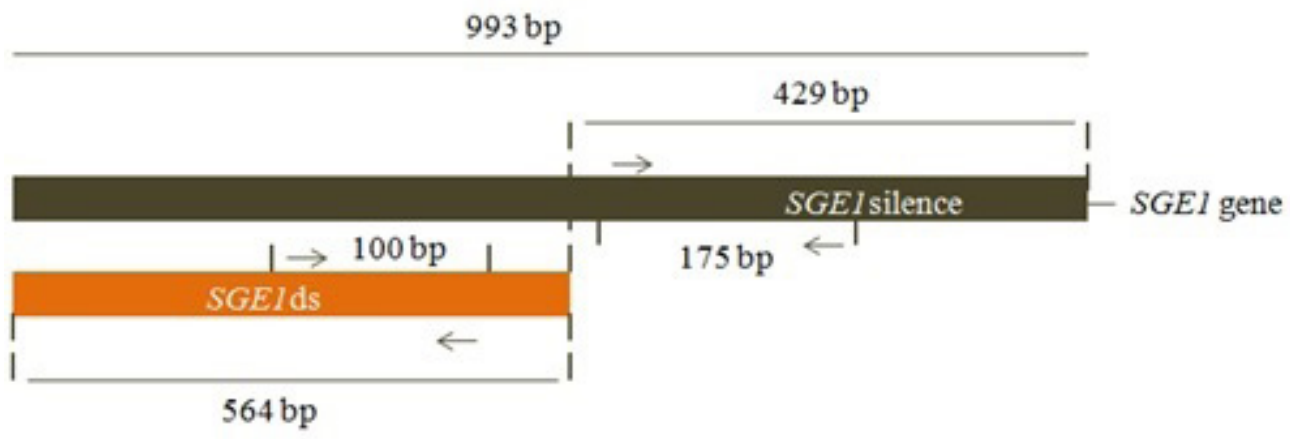

Figure 1. Scheme for the molecular characterization of the selected strains using the real-time quantitative PCR method (RT-qPCR). Strategy adopted to analyze the silencing levels of the 13 strains selected resulting from transformation with the pFANTAi4 vector.

\section{Pathogenicity test}

Spore suspensions from two transformants, T4 and T11 (resulting from the agrotransformation of spores and protoplasts), and the wild-type Foc strain were used to evaluate pathogenicity. The inoculation was performed using banana cv. Maçã plants. The plants were approximately $20 \mathrm{~cm}$ long, with roots washed and cut at the ends to facilitate fungal penetration. Plants were placed in beakers containing $150 \mathrm{~mL}$ spore suspension at a concentration of $10^{6}$ spores $/ \mathrm{mL}$. The banana plants used as a control were placed in autoclaved ultrapure water. The plants remained in solution for $2 \mathrm{~h}$ and were subsequently planted in polystyrene cups containing 
sterile sand. Plants were kept at $25^{\circ} \mathrm{C}$ during the day and $22^{\circ} \mathrm{C}$ during the night with a $12 \mathrm{~h}$ photoperiod, and received Hoagland nutrient solution every 15 days. All tests were performed in triplicate. Symptoms were evaluated after 45 days of inoculation according to methods described by Mak et al. (2004), where a 1-5 scale was followed for external symptoms, and a 1-8 scale was used for internal symptoms.

\section{Post-inoculation, reisolation, and characterization of transformants}

The reisolation of transformants from inoculated banana plants was performed using root, rhizome, and pseudostem fragments. Fragments were placed on Petri dishes containing agarwater, and incubated at $25^{\circ} \mathrm{C}$ for 2 days. Following fungi growth, slices of the agar (approximately 0.5 $\mathrm{mm}^{2}$ ) were transferred to plates containing PDA supplemented with hygromycin $\mathrm{B}$, and incubated for 3 days in a BOD incubator at $25^{\circ} \mathrm{C}$. Fungi able to grow in selective medium were subjected to the monospore culture process. Total DNA was extracted after 7 days of growth in PDA to confirm the transformants, and PCR was performed using primers to detect $h p h$ and SGE1 (Table 1).

\section{RESULTS}

\section{Phenotypic and molecular characterization of transformants}

In the different transformation experiments, transformant strains were only produced from protoplasts and spores with $96 \mathrm{~h}$ of co-culture and at $0.6 \mathrm{OD}_{600 \mathrm{~nm}}$. In total, 13 of the 120 monospore transformants maintained in selective medium with $130 \mu \mathrm{g} / \mathrm{mL}$ hygromycin $B$ were selected for further evaluation.

PCR evaluation of the selected transformants confirmed the presence of approximately 690-bp fragments corresponding to the hph gene, which indicated the presence of the cassette containing sense and antisense sequences of SGE1 for the production of the dsRNA hairpin. Furthermore, all isolates analyzed in the mitotic stability test for T-DNA insertions in the genome retained the ability to grow in the presence of hygromycin $B$, and this demonstrated genetic stability among the isolates, albeit with variations in radial colony growth. This was observed for isolates derived from both spores and protoplasts, except for the T4 and T7 transformants. Specifically, the T4 and T7 exhibited radial sizes very similar to that assessed for the wild-type Foc strain.

The effect of silencing on the conidiogenesis of transformants was evaluated in comparison to that of the wild-type strain, which had a spore concentration greater than $10^{6} \mathrm{spores} / \mathrm{mL}$ after 3 days of culture in liquid medium. At five days, the transformants had reached a mean growth ranging from 0.24 to $0.56 \times 10^{6}$ spores $/ \mathrm{mL}$, which was approximately $95 \%$ fewer spores than the wild-type strain (approximately $5.25 \times 10^{6} \mathrm{spores} / \mathrm{mL}$ at 5 days). Transformants were only able to reach a concentration of $10^{6}$ spores $/ \mathrm{mL}$ on the seventh day, whereas this concentration was reached by the wild-type strain after 3 days of growth. Differences in spore production between transformants and the wild-type strain were significant according to the Tukey test $(P=0.001)$. The transformant strains were also considered statistically equivalent (Figure 2).

\section{Evaluation of SGE1 gene silencing levels in transformed Foc strains}

Most transformants analyzed before the mitotic stability test showed no significant increase in relative expression of the region used for dsRNA production. SGE1 gene silencing was also not 
observed, which demonstrated that during this period (approximately 30 days after transformation), the dsRNA hairpin expression was insufficient to reduce SGE1 mRNA levels.

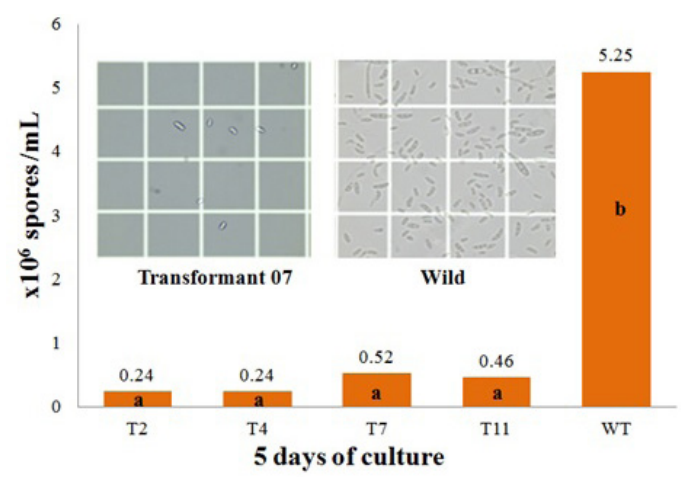

Figure 2. Effect of silencing on conidiogenesis. A. Spore count of wild-type (WT) and T7 transformant strains using a Neubauer chamber under an optical microscope with a 40X objective. B. Microconidium production of transformant and WT strains for 5 days of culturing in $1 / 4$ PDB medium at a concentration of $10^{5}$ spores $/ \mathrm{mL}$. Strains T2, T4, T7 and T11 (a) are considered statistically equal, according to the Tukey test, and significantly different from WT (b).

In contrast, considerable increases in the expression levels of the region used to produce the dsRNA hairpin were observed after the stability test in 9 transformants (T1, T2, T3, T4, T6, T7, T9, T10, and T11). However, significant reductions in the relative expression level of the SGE1 gene were not observed in the T1, T3, T9, T10, and T11 strains. Increased relative expression levels of the dsRNA hairpin were observed in the T6 and T12 strains; however, an increase in target mRNA transcript levels was also observed. The T2, T4, and T7 strains exhibited the highest levels of silencing of the target mRNA transcript, which was assessed using the SGE1 silence primers, and each of these strains resulted from the transformation of spores. Silencing was $30 \%$ for the T2 strain, $27 \%$ for the T4 strain, and $47 \%$ for the T7 strain (Figure 3). These values were calculated using the $2^{-\Delta \Delta C t}$ method normalized to reference genes, and represent the mean relative quantification values.

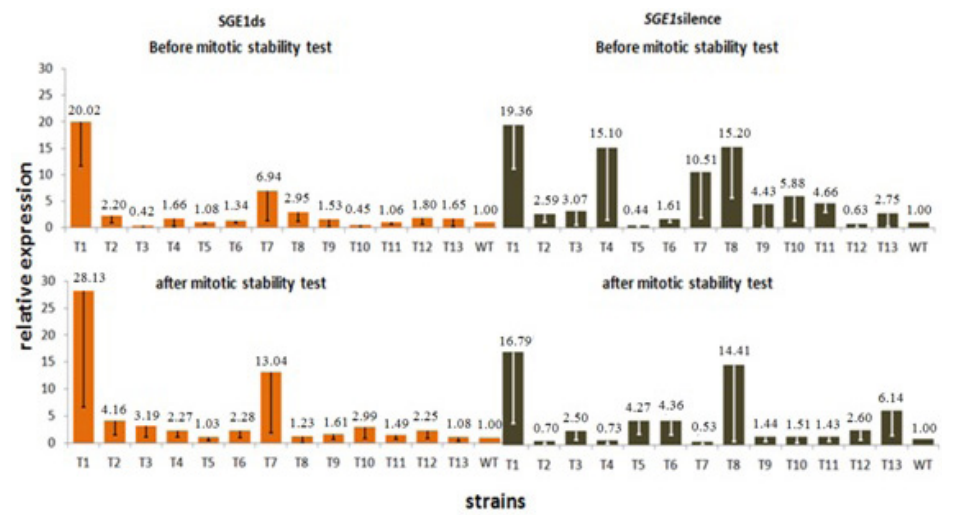

Figure 3. Diagram of the relative expression levels of dsRNA and SGE1 gene silencing before and after the mitotic stability test. In orange, dsRNA expression levels before (top diagram) and after (bottom diagram) the mitotic stability test in T1-T13 and wild-type (WT) strains. In brown, target mRNA expression levels before (top diagram) and after (bottom diagram) the mitotic stability test in T1-T13 and WT strains. 


\section{Analysis of SGE1 gene silencing in pathogenicity and/or virulence}

The T4 and T11 strains were selected for the inoculation of banana plants. These strains showed low levels of dsRNA transcripts before the mitotic stability test. An increase in dsRNA relative expression levels in T4, which exhibited radial colony growth similar to that of the wild-type strain, occurred during the growth period after the mitotic stability test. The sporulation capacity of T4 was quantitatively affected, as observed in the sporulation test; however, the spores produced were perfectly viable and able to germinate and produce hyphae. However, sporulation was reduced in T11 compared to wild-type Foc, and radial colony growth was also smaller than those of the T4 and wild-type strains, indicating that the cassette was possibly inserted into a region of the genome that affected mycelial growth.

In the pathogenicity test, banana plants inoculated with wild-type Foc began to show the first external disease symptoms at 10 days after inoculation. Yellowing of older leaves was observed, which subsequently progressed to younger leaves, and these symptoms are typical of Panama disease. In contrast, symptoms began to appear at 20 days after inoculation in banana plants inoculated with the T4 transformant strains, demonstrating that the $27 \%$ SGE1 gene silencing observed in T4 was able to delay symptoms. Additionally, Banana plants inoculated with the wild-type strain had advanced indices of external disease symptoms at 25 days after inoculation. Particularly, according to the symptom index scale, wild-type Foc induced symptoms at scores of 4 to 5 , and nearly all leaves were compromised and appeared yellowed to completely dry. Conversely, plants inoculated with strains T4, T11, and control plants had scores ranging from 2 to 3. At 30 days after inoculation, banana plants inoculated with the wild-type strain already showed total compromise in leaves with symptoms. Such plants displayed the common features of Panama disease, including a score of 5 on the disease scale. However, banana plants inoculated with transformant strains showed only the initial stages of disease, with few symptomatic leaves. In the evaluation of internal symptoms, infection was visible in the pseudostem and rhizome of banana plants inoculated with the wild-type strain. Such plants differed in color to banana plants inoculated with transformants at 45 days after inoculation. Banana plants inoculated with transformant strains followed virtually the same pattern as control banana plants, in which little pseudostem discoloration was observed, earning a score of 3 on the rhizome discoloration scale. Banana plants inoculated with the wild-type strain had rhizomes with scores ranging from 7 to 8 on the internal symptoms scale at 4 to 5 weeks after inoculation (Figure 4).

The ability of transformants to penetrate and colonize host tissues was evaluated by reisolation and analysis of inoculated transformants. The results confirmed the presence of transformants, both in rhizomes and pseudostems. However, wild-type Foc and Foc transformants could not be reisolated from roots. The transformants were transferred to Petri dishes containing culture medium with antibiotics and maintained the same morphological characteristics as the strains used in the inoculation.

\section{DISCUSSION}

RNAi mechanisms are often involved in protecting the genome of plants, animals, and eukaryotic microorganisms (Carreras-Villaseñor et al., 2013). These mechanisms have been conserved throughout evolution and may also act on regulatory processes, such as development, transcription, and translation (Meyer, 2008; Carreras-Villaseñor et al., 2013). 


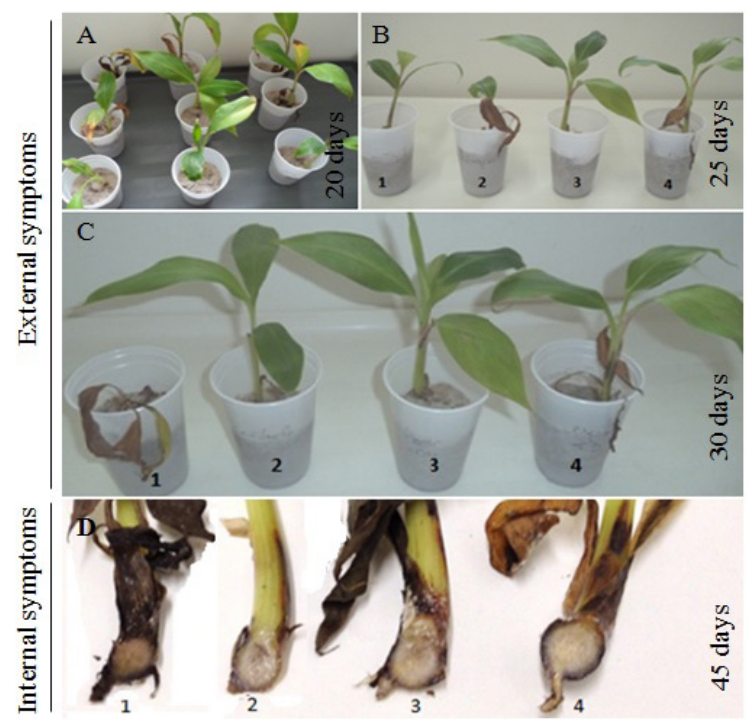

Figure 4. Symptoms in banana plants. External symptoms in A, B and C and internal symptoms in D. A. Bananas inoculated with the wild-type (WT) strain showed a higher disease severity score at 20 days after inoculation than bananas inoculated with transformant strains (columns from left to right: bananas inoculated with WT, T11, or T4). B. At 25 days after inoculation, most leaves on banana 2 were dry (banana 1- control; 2- WT; 3- T11; and 4- T4). C. At 30 days after inoculation, banana 1 was dead. Bananas 3 and 4 showed initial disease stages (banana 1- WT; 2control; 3- T11; and 4- T4). D. Pseudostem cross-sections at 45 days after inoculation. Pseudostem 1 has a higher discoloration score (banana 1- WT; 2- control; 3- T11; and 4- T4).

Post-transcriptional silencing by RNAi is based on the formation of dsRNA molecules, which are cleaved by Dicer-like (Dcl) enzymes into siRNAs of approximately 20-25 nucleotides in length. siRNA is then incorporated into Argonaut (Ago) proteins, which are located in the RNA Interference Specificity Complex. Sense and antisense siRNA molecules are then separated. Only the antisense molecules remain in the complex, guiding them to complementary mRNA sequences, which causes the degradation of the target mRNAs (Schumann et al., 2013).

Different strategies have been used in RNAi silencing, including the use of several types of transformation vectors, and the direct use of dsRNAs and siRNAs synthesized in vitro. One of the few published studies utilizing the Foc RNAi mechanism used synthetic dsRNA molecules against different genes to evaluate their effects on spore germination and colony establishment, and 79.8 to $93 \%$ inhibition was observed among the 14 genes tested. Specifically, dsRNAs against the mRNAs of adenylate cyclase and the alpha subunit of DNA polymerase delta resulted in the highest levels of spore germination inhibition (Mumbanza et al., 2013). Reaching such high gene silencing levels demonstrates the potential of this method. While the use of synthetic dsRNAs is fast, and various kits are available on the market, this silencing methods is costly and transient.

Given the need to evaluate the effects of gene silencing over longer periods of time, such as those on phenotypic changes, we used a transformation strategy utilizing a cassette that induced the formation of a dsRNA hairpin. This strategy has the advantage of ensuring a constant production of siRNA through cellular machinery. Therefore, the expression of the dsRNA against the targeted gene is permanent when the insertion of the cassette into the fungal genome is stable.

The transformant strains prepared in the current study maintained stable cassette 
integration in the genome following the mitotic stability test. However, variations in radial colony growth were observed for some of the transformed strains. Such variations are not characteristic of SGE1 silencing. For example, mutants generated upon SGE1 gene deletion showed a vegetative growth indistinguishable from that of wild-type Fol according to Michielse et al. (2009). Similar results were obtained for the T4 transformant in the present study. However, the T11 strain had significantly lower radial colony growth than those of the T4 and wild-type strains. This may have been because the cassette had no target region for integration into the genome, and thus the integration may have interrupted or altered the expression of a gene important for growth. Countless studies involving filamentous fungi, including F. oxysporum (Martín-Udíroz et al., 2004), F. graminearum (Connolly et al., 2013), and Leptosphaeria maculans (Feng et al., 2014), found that interrupting genes encoding enzymes and proteins important for metabolism may result in a reduced capacity for growth using specific carbon sources, and may change pigmentation. Components of fungal pathogenicity, such as sporulation and spore germination, may also be adversely affected, and this in turn reduces virulence in the host plant (Feng et al., 2014).

Although Michielse et al. (2009) observed that SGE1 is not required for vegetative growth or the utilization of different carbon sources in Fol, this gene was demonstrated to be quantitatively involved in conidiogenesis. The spores generated by SGE1 mutants are less abundant, but perfectly viable. Similar observations were also made here for Foc transformants when compared to wild-type Foc. After three days of culture in $1 / 4$ strength PDB, the wild-type strain had a spore concentration greater than $10^{6} \mathrm{spores} / \mathrm{mL}$, while transformant strains required at least five days of culture to reach concentrations of $10^{5} \mathrm{spores} / \mathrm{mL}$. Seven days of culture were required for transformed strains, including T4 and T11, to reach the same concentration reached by the wild-type strain in 3 days. However, changes in conidial size/structure were not observed for the transformed lines described herein.

Given the complexity and large number of genes involved in conidiogenesis, transformants that exhibited no SGE1 gene silencing but with reduced numbers of conidia may result from other factors. The various possibilities should thus be examined, including the identification of the T-DNA insertion region in the different transformants. In F. oxysporum f. sp. melonis, 42 genes that are significantly involved in conidiogenesis have been identified. These include FVS1, which encodes a protein with a SAM domain that is commonly involved in protein-protein interactions, important for transcriptional and post-transcriptional regulation and signal transduction. fVs 1 mutants produced morphologically normal microconidia and macroconidia, but despite normal conidia were produced in a markedly reduced number in the mutant than in the wild type. Mutants also displayed defects in conidial germination and virulence (lida et al., 2014).

Among all the transformants tested, three strains showed considerably reduced expression levels of the target transcript. Specifically, the T4, T2, and T7 strains showed 27, 30, and $47 \%$ targeted gene silencing, respectively, and simultaneously expression of the gene region included in the transformation cassette was increased when compared to that of the wild-type strain. Similar results have been observed in other studies of filamentous fungi. For example, targeted gene silencing ranged from 15 to 96\% in Phanerochaete chrysosporium (Matityahu et al., 2008) and 18.4 to $97 \%$ in Trichoderma atroviride (Carreras-Villaseñor et al., 2013).

The difference among the transformants may be related to low dsRNA production due to epigenetic factors as different expression levels of dsRNAs and targeted gene transcripts were detected before and after the mitotic stability test by RT-qPCR. A second hypothesis is that 20-30 days following cassette integration into the genome was insufficient for maximum dsRNAexpression in some transformed strains. For example, in Moniliophthora perniciosa, gfp gene silencing with 
constitutively expressed dsRNA was initially detected at 28 after transformation (Caribé dos Santos et al., 2009). However, Goldoni et al. (2004) concluded that transcript repression may be an efficient process, even when expression levels of the dsRNA hairpin are low.

Regardless of the degree of decrease in SGE1 expression relative to that of the wildtype strain, a visible reduction in virulence was observed during the pathogenicity test. Reduced virulence was even observed in the T11 strain, which showed similar relative expression of SGE1 to that of the wild-type strain, but with pathogenicity in banana plants similar to that of the T4 transformant whose SGE1 expression was significantly reduced compared to that of the wildtype strain. Taken together, the data indicate that transformants and wild-type strains managed to penetrate the roots and colonize the host plants. Infection then extended into the vascular system. These data were confirmed by the isolation of the strains from the rhizome and pseudostem of banana plants, demonstrating that the symptoms were actually caused by the presence of the fungi inoculated into the host plants. The progression of symptoms was slower in plants inoculated with the transformants in comparison to plants inoculated with the wild-type strain. This indicates that SGE1 gene silencing does not prevent symptoms from appearing, but rather that symptoms are delayed. Michielse et al. (2009) evaluated the same pathogen-host plant interaction using deletion mutants and confirmed the importance of SGE1 in pathogenicity and/or virulence as Fol transformants had difficulty proceeding into the vascular system of infected tomato plants.

The visible reduction in virulence observed when SGE1 is silenced indicates that this gene also plays a key role in the development of disease in Foc. Furthermore, this gene may serve as target for the development of pathogen control alternatives using host-induced gene silencing (HIGS). The HIGS method has been found to severely reduce the damage caused by plant pathogens in plants of agronomic interest (Tinoco et al., 2010; Ghag et al., 2014; Cheng et al., 2015). HIGS has demonstrated that RNAi may spread systemically, moving from host plant cells to invading pathogen cells, promoting the silencing of specific genes.

\section{Conflicts of interest}

The authors declare no conflict of interest.

\section{ACKNOWLEDGMENTS}

The Graduate Program in Biotechnology at Amazonas State University (Pós-graduação em Biotecnologia da Universidade do Estado do Amazonas - PPG-MBT, UEA) and the Brazilian Agricultural Research Corporation Western Amazon, Molecular Biology Laboratory (Empresa Brasileira de Pesquisa Agropecuária (Embrapa) Amazônia Ocidental, Lab. Bio. Mol.) participated in this study. Research supported by the Amazonas State Research Foundation (Fundação de Amparo à Pesquisa do Estado do Amazonas - FAPEAM), Public Notice of the Program for the Support of Scientific Publications (Edital Programa de Apoio à Publicação de Artigos Científicos - PAPAC), and the National Council for Scientific and Technological Development (Conselho Nacional de Desenvolvimento Científico e Tecnológico - CNPq). We also thank Dr. Miguel Dita (Embrapa) for kindly providing the Foc isolates.

\section{REFERENCES}

Bhadauria V, Banniza S, Wei Y and Peng YL (2009). Reverse genetics for functional genomics of phytopathogenic fungi and oomycetes. Comp. Funct. Genomics 2009: 380719. http://dx.doi.org/10.1155/2009/380719 
Caribé dos Santos AC, Sena JA, Santos SC, Dias CV, et al. (2009). dsRNA-induced gene silencing in Moniliophthora perniciosa, the causal agent of witches' broom disease of cacao. Fungal Genet. Biol. 46: 825-836. http://dx.doi.org/10.1016/j. fgb.2009.06.012

Carreras-Villaseñor N, Esquivel-Naranjo EU, Villalobos-Escobedo JM, Abreu-Goodger C, et al. (2013). The RNAi machinery regulates growth and development in the filamentous fungus Trichoderma atroviride. Mol. Microbiol. 89: 96-112. http:// dx.doi.org/10.1111/mmi.12261

Cheng W, Song XS, Li HP, Cao LH, et al. (2015). Host-induced gene silencing of an essential chitin synthase gene confers durable resistance to Fusarium head blight and seedling blight in wheat. Plant Biotechnol. J. 13: 1335-1345 http://dx.doi. org/10.1111/pbi.12352.

Connolly LR, Smith KM and Freitag M (2013). The Fusarium graminearum histone H3 K27 methyltransferase KMT6 regulates development and expression of secondary metabolite gene clusters. PLoS Genet. 9: e1003916. http://dx.doi.org/10.1371/ journal.pgen.1003916

Cordeiro ZJM and Matos AP (2003). Panama disease Fim do bananal (Cultivar HF, ed.). EMBRAPA Mandioca e Fruticultura, Brasilia, 27-29.

Doyle JJ and Doyle JL (1990). Isolation of plant DNA from fresh tissue. Focus 12: 13-14.

Elbashir SM, Lendeckel W and Tuschl T (2001). RNA interference is mediated by 21- and 22-nucleotide RNAs. Genes Dev. 15: 188-200. http://dx.doi.org/10.1101/gad.862301

FAO (2014). Food and Agriculture Organization of the United Nations, Database. Available at http://www.fao.org/news/story/en/ item/223409/icode/. Accessed August, 2015.

Feng J, Zhang H, Strelkov SE and Hwang SF (2014). The LmSNF1 gene is required for pathogenicity in the canola blackleg pathogen Leptosphaeria maculans. PLoS One 9: e92503. http://dx.doi.org/10.1371/journal.pone.0092503

Fire A, Xu S, Montgomery MK, Kostas SA, et al. (1998). Potent and specific genetic interference by double-stranded RNA in Caenorhabditis elegans. Nature 391: 806-811. http://dx.doi.org/10.1038/35888

França NR, Mesquita Júnior D, Lima AB, Pucci FVC, et al. (2010). Interferência por RNA: Uma nova alternativa para terapia nas doenças reumáticas. Rev. Bras. Reumatol. 50: 695-709. http://dx.doi.org/10.1590/S0482-50042010000600008

Ghag SB, Shekhawat UK and Ganapathi TR (2014). Host-induced post-transcriptional hairpin RNA-mediated gene silencing of vital fungal genes confers efficient resistance against Fusarium wilt in banana. Plant Biotechnol. J. 12: 541-553. http:// dx.doi.org/10.1111/pbi.12158

Goldoni M, Azzalin G, Macino G and Cogoni C (2004). Efficient gene silencing by expression of double stranded RNA in Neurospora crassa. Fungal Genet. Biol. 41: 1016-1024. http://dx.doi.org/10.1016/j.fgb.2004.08.002

Guo L, Han L, Yang L, Zeng H, et al. (2014). Genome and transcriptome analysis of the fungal pathogen Fusarium oxysporum $\mathrm{f}$. sp. cubense causing banana vascular wilt disease. PLoS One 9: e95543. http://dx.doi.org/10.1371/journal.pone.0095543

lida Y, Fujiwara K, Yoshioka Y and Tsuge T (2014). Mutation of FVS1, encoding a protein with a sterile alpha motif domain, affects asexual reproduction in the fungal plant pathogen Fusarium oxysporum. FEMS Microbiol. Lett. 351: $104-112$. http://dx.doi.org/10.1111/1574-6968.12356

Ketting RF, Haverkamp TH, van Luenen HG and Plasterk RH (1999). Mut-7 of C. elegans, required for transposon silencing and RNA interference, is a homolog of Werner syndrome helicase and RNaseD. Cell 99: 133-141. http://dx.doi.org/10.1016/ S0092-8674(00)81645-1

Krajaejun T, Gauthier GM, Rappleye CA, Sullivan TD, et al. (2007). Development and application of a green fluorescent protein sentinel system for identification of RNA interference in Blastomyces dermatitidis illuminates the role of septin in morphogenesis and sporulation. Eukaryot. Cell 6: 1299-1309. http://dx.doi.org/10.1128/EC.00401-06

Lievens B, Houterman PM and Rep M (2009). Effector gene screening allows unambiguous identification of Fusarium oxysporum f. sp. lycopersici races and discrimination from other formae speciales. FEMS Microbiol. Lett. 300: 201-215. http://dx.doi.org/10.1111/j.1574-6968.2009.01783.x

Mak C, Mohamed AA, Liew KW and Ho YW (2004). Early screening technique for Fusarium wilt resistance in banana micropropagated plants. In: Banana Improvement: Cellular, Molecular Biology, and Induced Mutations (Jain SM and Swennen R, eds.). Enfield, Science Publishers, INC., Enfield, NH, USA, chap. 18.

Martín-Udíroz M, Madrid MP and Roncero MI (2004). Role of chitin synthase genes in Fusarium oxysporum. Microbiology 150: 3175-3187. http://dx.doi.org/10.1099/mic.0.27236-0

Matityahu A, Hadar Y, Dosoretz CG and Belinky PA (2008). Gene silencing by RNA Interference in the white rot fungus Phanerochaete chrysosporium. Appl. Environ. Microbiol. 74: 5359-5365. http://dx.doi.org/10.1128/AEM.02433-07

Meyer V (2008). Genetic engineering of filamentous fungi--progress, obstacles and future trends. Biotechnol. Adv. 26: 177-185. http://dx.doi.org/10.1016/j.biotechadv.2007.12.001

Meldrum RA, Fraser-Smith S, Tran-Nguyen LTT, Daly AM, et al. (2012). Presence of putative pathogenicity genes in isolates of Fusarium oxysporum f. sp. cubense from Australia. Australas. Plant Pathol. 41: 551-557. http://dx.doi.org/10.1007/ $\underline{\text { s13313-012-0122-x }}$ 
Michielse CB, van Wijk R, Reijnen L, Manders EMM, et al. (2009). The nuclear protein Sge1 of Fusarium oxysporum is required for parasitic growth. PLoS Pathog. 5: e1000637. http://dx.doi.org/10.1371/journal.ppat.1000637

Mumbanza FM, Kiggundu A, Tusiime G, Tushemereirwe WK, et al. (2013). In vitro antifungal activity of synthetic dsRNA molecules against two pathogens of banana, Fusarium oxysporum f. sp. cubense and Mycosphaerella fijiensis. Pest Manag. Sci. 69: 1155-1162. http://dx.doi.org/10.1002/ps.3480

Napoli C, Lemieux C and Jorgensen R (1990). Introduction of a Chimeric Chalcone Synthase Gene into Petunia Results in Reversible Co-Suppression of Homologous Genes in trans. Plant Cell 2: 279-289. http://dx.doi.org/10.1105/tpc.2.4.279

Ploetz R and Pegg K (1997). Fusarium wilt of banana and Wallace's line: was the disease originally restricted to his IndoMalayan region? Australas. Plant Pathol. 26: 239-249. http://dx.doi.org/10.1071/AP97039

Rep M, van der Does HC, Meijer M, van Wijk R, et al. (2004). A small, cysteine-rich protein secreted by Fusarium oxysporum during colonization of xylem vessels is required for I-3-mediated resistance in tomato. Mol. Microbiol. 53: 1373-1383. http://dx.doi.org/10.1111/j.1365-2958.2004.04177.x

Romano N and Macino G (1992). Quelling: transient inactivation of gene expression in Neurospora crassa by transformation with homologous sequences. Mol. Microbiol. 6: 3343-3353. http://dx.doi.org/10.1111/j.1365-2958.1992.tb02202.x

Schumann U, Smith NA, Kazan K, Ayliffe M, et al. (2013). Analysis of hairpin RNA transgene-induced gene silencing in Fusarium oxysporum. Silence 4: 3. http://dx.doi.org/10.1186/1758-907X-4-3

Shafran H, Miyara I, Eshed R, Prusky D, et al. (2008). Development of new tools for studying gene function in fungi based on the Gateway system. Fungal Genet. Biol. 45: 1147-1154. http://dx.doi.org/10.1016/j.fgb.2008.04.011

Sutherland R, Viljoen A, Myburg AA and van den Berg N (2013). Pathogenicity associated genes in Fusarium oxysporum f. sp. cubense race 4. S. Afr. J. Sci. 109: 1-10. http://dx.doi.org/10.1590/sajs.2013/20120023

Tinoco ML, Dias BB, Dall'Astta RC, Pamphile JA, et al. (2010). In vivo trans-specific gene silencing in fungal cells by in planta expression of a double-stranded RNA. BMC Biol. 8: 27. http://dx.doi.org/10.1186/1741-7007-8-27

Visser M, Gordon TR, Wingfield BD, Wingfield MJ, et al. (2004). Transformation of Fusarium oxysporum f. sp. cubense, causal agent of Fusarium wilt of banana, with the green fluorescent protein (GFP) gene. Australas. Plant Pathol. 33: 69-75. http:// dx.doi.org/10.1071/AP03084

Zwiers LH and De Waard MA (2001). Efficient Agrobacterium tumefaciens-mediated gene disruption in the phytopathogen Mycosphaerella graminicola. Curr. Genet. 39: 388-393. http://dx.doi.org/10.1007/s002940100216 